\title{
CIRCULATING LEVELS OF OESTRADIOL-17 $\beta$ DURING EARLY PREGNANCY IN THE ALASKAN FUR SEAL SHOWING AN OESTROGEN SURGE PRECEDING IMPLANTATION
}

\author{
J. C. DANIEL, JR \\ Department of Zoology, University of Tennessee, Knoxville, Tennessee, U.S.A.
}

(Received 16th October 1973)

From morphological, physiological and biochemical observations, Shelesnyak, Kraicer \& Zeilmaker (1963) demonstrated the existence of an 'oestrogen surge' in the rat occurring on Day 3 of either pregnancy or pseudopregnancy (spermatozoa in the vaginal smear on Day 0 ). This observation was confirmed by Shaikh \& Abraham (1969) with radioimmunoassay for oestradiol concentration in ovarian venous blood plasma. The oestrogen surge coincides with the period of blastocyst development immediately preceding implantation. Furthermore, an artificial surge produced by exogenous oestradiol-17 $\beta$ in rodents ovariectomized before Day 3 terminates a state of facultative delayed implantation by reactivation of blastocysts in diapause (Cochrane \& Meyer, 1957).

McLaren (1972) has suggested that " .... the necessity for an oestrogenic intervention at the time of implantation, ....., may be characteristic of those species where the embryo undergoes delayed implantation". We were interested in determining whether a representative of a group having obligatory delayed implantation might also have an oestrogen surge which coincided with the period or reactivation of blastocyst growth immediately before implantation, and how the levels of circulating oestrogen varied during early pregnancy in that species. This paper reports the results of a study using blood plasma samples from the Alaskan fur seal (Callorhinus ursinus).

In 1971 and 1972, blood samples were collected during the period of blastocyst dormancy and early postimplantation (July to December) from thirtyeight adult female fur seals which were trapped on the Pribilof Islands, Alaska or had returned to the sea. Where possible, the stages of early pregnancy were represented by three to five seals (see Text-fig. 1). All samples were stored frozen and shipped in dry ice to the author's laboratory at the University of Tennessee. There they were thawed, centrifuged, and oestrogen concentrations were determined on the plasma supernatant by use of a variation of the technique described by Mikhail, Wu, Ferin \& Vande Wiele (1970). The variation involves using activated charcoal as an absorbent for antibody-bound oestrogens (P. Coulson, personal communication). This method has an extraction efficiency of about $64 \%$ for oestradiol- $17 \beta$ and a sensitivity as low as $5 \mathrm{pg}$. The cross reactivity with other steroids is low, being specifically $1 \%$ for progesterone, $10 \%$ 
to $15 \%$ for oestriol and $30 \%$ to $35 \%$ for oestrone. Comparable human values using this technique on pooled plasma show about $17 \mathrm{pg} / \mathrm{ml}$ for males and $145 \mathrm{pg} / \mathrm{ml}$ for females.

The results are shown in Text-fig. 1, which also includes the growth curve for the fur seal embryo (taken from Daniel, 1971). Craig (1964) reported that implantation in the fur seal occurred from early to mid-November, an observation substantiated by coincidental accelerated growth of the embryo (Daniel,
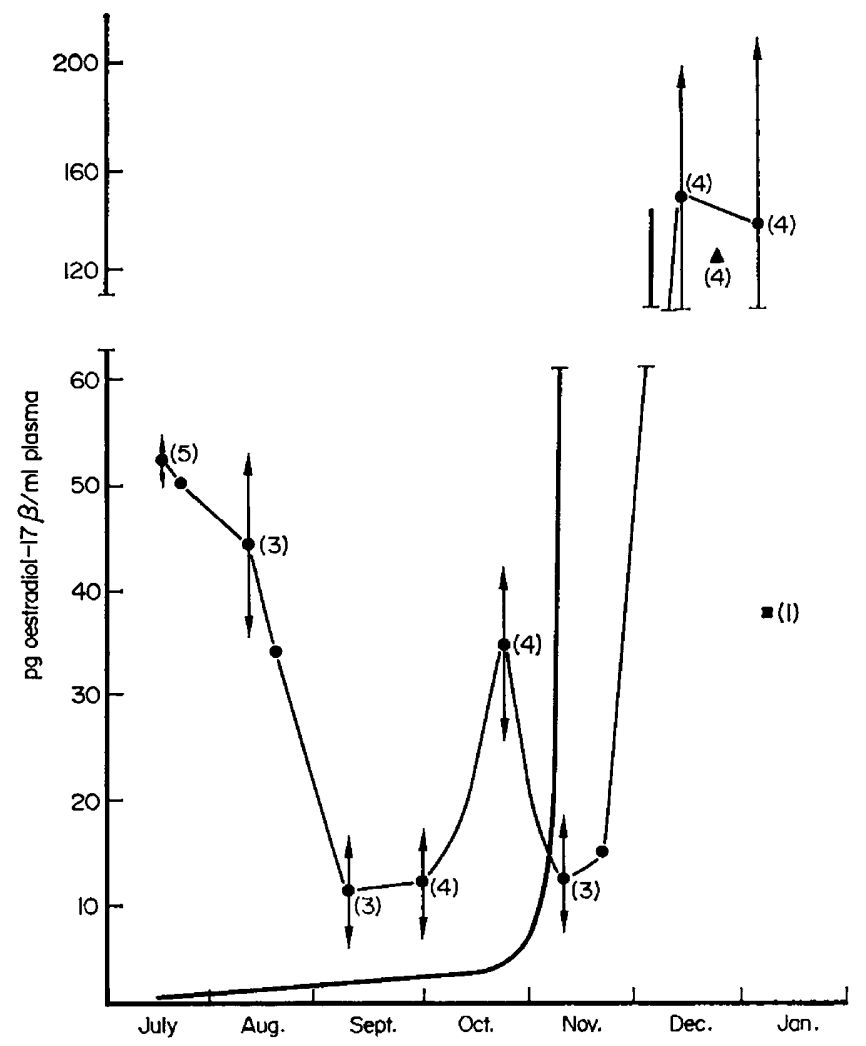

Text-Fig. 1. Concentration of oestradiol-17 $\beta$ in the peripheral blood plasma of the Alaskan fur seal during the first 6 months of pregnancy. The heavy line represents the growth curve of the embryo (from Daniel, 1971) for this same period. Arrow-headed vertical lines show standard error. $\mathbf{\Delta}$, Mean oestradiol concentration of a group of four pseudopregnant animals (i.e. had well-developed copora lutea but no embryos).

Oestradiol concentration of one non-pregnant female without a corpus luteum.

1971). It is clear that a prominent surge in oestrogen concentration occurs immediately before the time of blastocyst reactivation and accelerated growth leading to implantation. Because most samples were collected at $2 \frac{1}{2}$ - to 3-week intervals during this period, however, the timing of the surge, its duration, or its intensity could not be precisely described from these data.

The other unique feature of fur seal endocrinology shown by these data is the prolonged period of high oestrogen concentration following ovulation. Almost 
2 months are required before the concentrations are reduced to their lowest middelay period levels. Samples taken in December and January show a return to high levels as characteristic of postimplantation.

There are few convincing reports of 'oestrogen surges' occurring in the period immediately preceding implantation in mammalian species other than laboratory rodents. In both cow (Batson, 1972) and sheep (Cox, Mattner \& Thorburn, 1971), there is a secondary peak of oestrogen secretion after ovulation, specifically on Day 5 for the cow and Days 3 and 4 for sheep. Henricks, Dickey, Hill \& Johnston (1972) found that oestrogen levels in mated cows that returned to oestrus increased to a minor peak on Day 9 but in pregnant cows the level stayed low at least through 39 days of gestation. According to Hilliard \& Eaton, (1971), in the rabbit " . . implantation is preceded by a small rise in estrogen production" between the 4th and 6th days post coitum, but Challis, Davis \& Ryan (1973) maintain that the concentration peak of oestradiol-17 $\beta$ seen on Day 6 is not statistically significantly different from that on Day 3. Mead \& Eik-Nes (1969) noted a gradual rise in oestradiol-17 $\beta$ concentration in the peripheral plasma of the spotted skunk before nidation with the level remaining elevated in postimplantation samples but the authors deny the existence of a 'surge'. Mikhail et al. (1970) found a "mid-cycle peak of estradiol of one or two days duration, occurring immediately prior to or coinciding with the LH peak" in the human.

The findings reported here demonstrate that the Alaskan fur seal, a mammal having obligatory delayed implantation, has an oestrogen surge near the end of that delay period.

The author wishes to express gratitude to Dr Patricia Coulson and Mr John Hathaway for technical assistance in the oestradiol assays, and to Dr Mark Keyes, Dr Al Roppel and Dr Michael Bigg for help in collecting the blood samples.

This work has been supported in part by Grant GB 37558 from the National Science Foundation.

\section{REFERENGES}

Batson, D. B. (1972) Progesterone and estrogen levels in the peripheral plasma of non-bred, non-pregnant and pregnant cows. Ph.D. thesis, University of Tennessee, Department of Animal Science.

Ghallis, J. R. G., Davis, I. J. \& Ryan, K. J. (1973) The concentrations of progesterone, estrone and estradiol-17 $\beta$ in the plasma of pregnant rabbits. Endocrinology, 93, 971.

Cochrane, R. L. \& Meyer, R. K. (1957) Delayed nidation in the rat induced by progesterone. Proc. Soc. exp. Biol. Med. 96, 155.

Cox, R. I., Mattner, P. E. \& Thorburn, G. D. (1971) Changes in ovarian secretion of oestradiol-17 $\beta$ around oestrus in the sheep. F. Endocr. 49, 346.

GraIG, A. M. (1964) Histology of reproduction and the estrus cycle in the female fur seal, Callorininus ursinus. F. Fish. Res. Bd. Can. 21, 773.

DANIEL, J. C. (1971) Growth of the preimplantation embryo of the northern fur seal and its correlation with changes in uterine protein. Devl Biol. 26, 315.

Henricks, D. M., Dickey, J. F., Hicl, J. R. \& Johnston, W. E. (1972) Plasma estrogen and progesterone levels after mating and during late pregnancy and postpartum in cows. Endocrinology, 90, 1336.

Hilliard, J. \& Eaton, L. W. (1971) Estradiol-17 $\beta$, progesterone and 20 $\alpha$-hydroxypregn-4-en-3-one in rabbit ovarian venous plasma. II. From mating through implantation. Endocrinology, 89, 532. 
Malaren, A. (1972) Endocrinology of implantation. Abstracts, 1st South-East Asia and Oceana med. sci. Congr. int. plann. Parent. Fedn, Sydney, p. 16.

Mead, R. A. \& Eik-Nes, K. B. (1969) Oestrogen levels in peripheral blood plasma of the spotted skunk, 7. Reprod. Fert. 18, 351.

Mikhail, G., Wu, G. H., Ferin, M. \& Vande Wiele, R. L. (1970) Radioimmunoassay of estrone and estradiol. Acta endocr., Copenh. Suppl. 147, 347.

Shaikh, A. A. \& Abraham, G. E. (1969) Measurement of estrogen surge during pseudopregnancy in rats by radioimmunoassay. Biol. Reprod. 1, 378.

Shelesnyak, M. G., Kraicer, P. F. \& Zeilmaker, G. H. (1963) Studies on the mechanism of decidualization. I. The oestrogen surge of pseudopregnancy and progravidity and its role in the process of decidualization. Acta endocr., Copenh. 42, 225. 